\title{
Type I choledochal cyst - an atypical presentation and an unusual association with single umbilical artery
}

Telema Nga ${ }^{1,2}$

Neelofar Abdullah ${ }^{1,2}$

Garrett Levin ${ }^{1,2}$

'Department of Pediatrics, Texas Tech University Health Sciences Center, El Paso, TX, USA; ${ }^{2}$ El Paso Children's Hospital, El Paso, TX, USA
Correspondence: Telema Nga Department of Pediatrics, Texas Tech University Health Science Center at El Paso, 480I Alberta Avenue, EI Paso,TX 79905, USA

Tel +l 6822017934

Email tetenga@ymail.com
This article was published in the following Dove Press journal:

Research and Reports in Neonatology

25 November 2014

Number of times this article has been viewed

\begin{abstract}
A unique case of an asymptomatic newborn with type I choledochal cyst and a single umbilical artery is reported. Ultrasound imaging was used as a screening tool and magnetic resonance cholangiopancreatography as a method of adequate visualization. On day 8 of life, the patient had a laparotomy with resection of choledochal cyst, cholecystectomy, and reconstruction using a jejunal Roux-en-Y to portal plate.
\end{abstract}

Keywords: choledochal cyst, single umbilical artery, cholecystectomy

\section{Introduction}

We report for the first time a case of an association between a single umbilical artery and choledochal cyst. The occurrence of single umbilical artery and gastrointestinal anomalies has been recorded, but - as far as we know - this is the first reported association of single umbilical artery with choledochal cyst in the literature.

\section{Case presentation}

This 39-week, appropriate for gestational age, male infant was born to a 23-year-old primigravida by spontaneous vaginal delivery. The newborn was awarded Apgar scores of 1,1 , and 2 at 1 minute, 5 minutes, and 10 minutes, respectively. The infant was transported to our facility for total body cooling due to perinatal asphyxia and hypoxic ischemic encephalopathy, and for ventilator management of respiratory distress from meconium aspiration.

Pregnancy was uneventful except for development of pregnancy-induced hypertension in labor. Prenatal laboratory findings were within normal limits. Biometrics were: birth weight, 2,830 grams (15\%); length, $51 \mathrm{~cm}(75 \%)$; and head circumference of $35.5 \mathrm{~cm}(75 \%)$. Vital signs were within normal limits.

Clinical exam revealed neither jaundice nor abdominal mass. Bilateral rales were heard in the chest, and an abdominal exam showed a single umbilical artery. Neurological exam was consistent with Sarnat stage 1 hypoxic-ischemic encephalopathy.

Laboratory studies performed included: a complete blood count, which was unremarkable; normal complete metabolic panel with electrolytes and glucose; and fractionated bilirubin (total bilirubin, $4.4 \mathrm{mg} / \mathrm{dL}$; direct bilirubin, $0.2 \mathrm{mg} / \mathrm{dL}$ ). Liver function tests were normal.

An echocardiogram showed peripheral pulmonic stenosis and patent foramen ovale. Cranial magnetic resonance imaging revealed right intraventricular hemorrhage and periventricular leukoencephalomalacia. An abdominal ultrasound (Figure 1) 
was performed to evaluate the single umbilical vessel. The sonogram showed a dilated bile duct, consistent with a type I choledochal cyst. The gallbladder appeared unremarkable. The common bile duct was dilated, measuring $3.7 \mathrm{~mm}$. It was dilated down to the level of the pancreatic head, where it measured $4.3 \mathrm{~mm}$. No definite stones were identified.

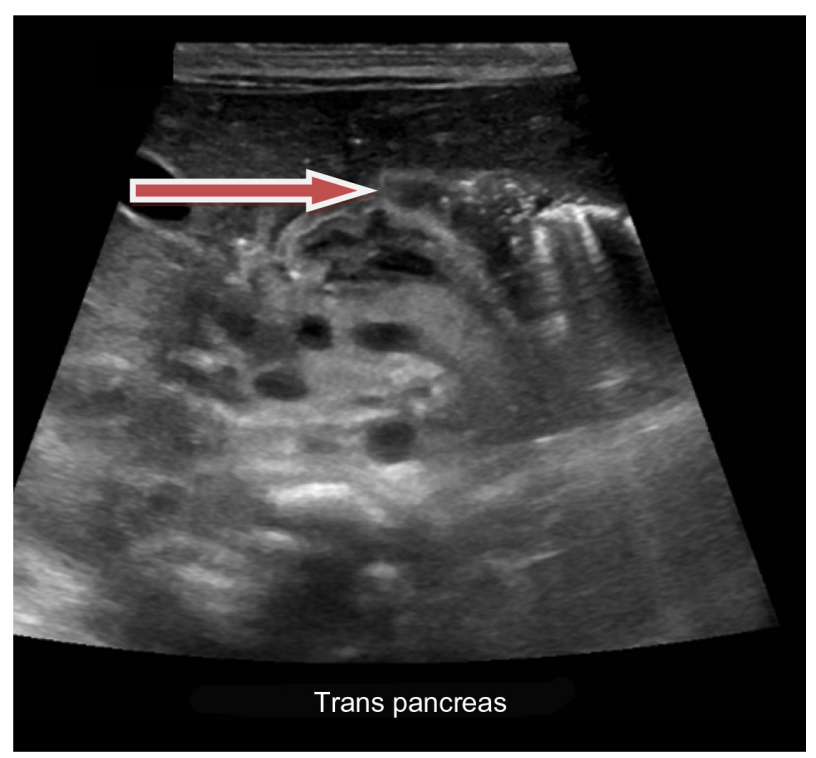

Figure I Abdominal ultrasound showing type I choledochal cyst.

Notes: Abdominal sonogram transverse view of pancreas. Arrow points to dilated bile duct measuring $4.3 \mathrm{~mm}$.
No intrahepatic biliary ductal dilatation was noted. Pancreas, aorta, inferior vena cava, and spleen were otherwise unremarkable. Both kidneys were normal in size and echogenicity, and showed no stones, masses, or hydronephrosis. The bladder was unremarkable.

A follow-up magnetic resonance cholangiopancreatography (Figure 2) revealed a type I choledochal cyst with slight extension involving the distal aspects of the right and left hepatic ducts.

On day 8 of life, the patient had laparotomy with resection of the choledochal cyst, cholecystectomy, and biliary reconstruction using a jejunal Roux-en-Y to the portal plate. He was started on parenteral nutrition and was gradually weaned to full enteral feeding. The infant was discharged home in a good clinical state.

\section{Discussion}

Our patient had a single umbilical artery with an associated type I choledochal cyst. A two-vessel umbilical cord (single umbilical artery) is a perinatal finding that may be associated with congenital or chromosomal anomalies. ${ }^{1}$

Fetuses and neonates with a single umbilical artery have been reported to have a 6.77 times greater risk of congenital anomalies and 15.35 times greater risk of chromosomal abnormalities than the general population. The most common

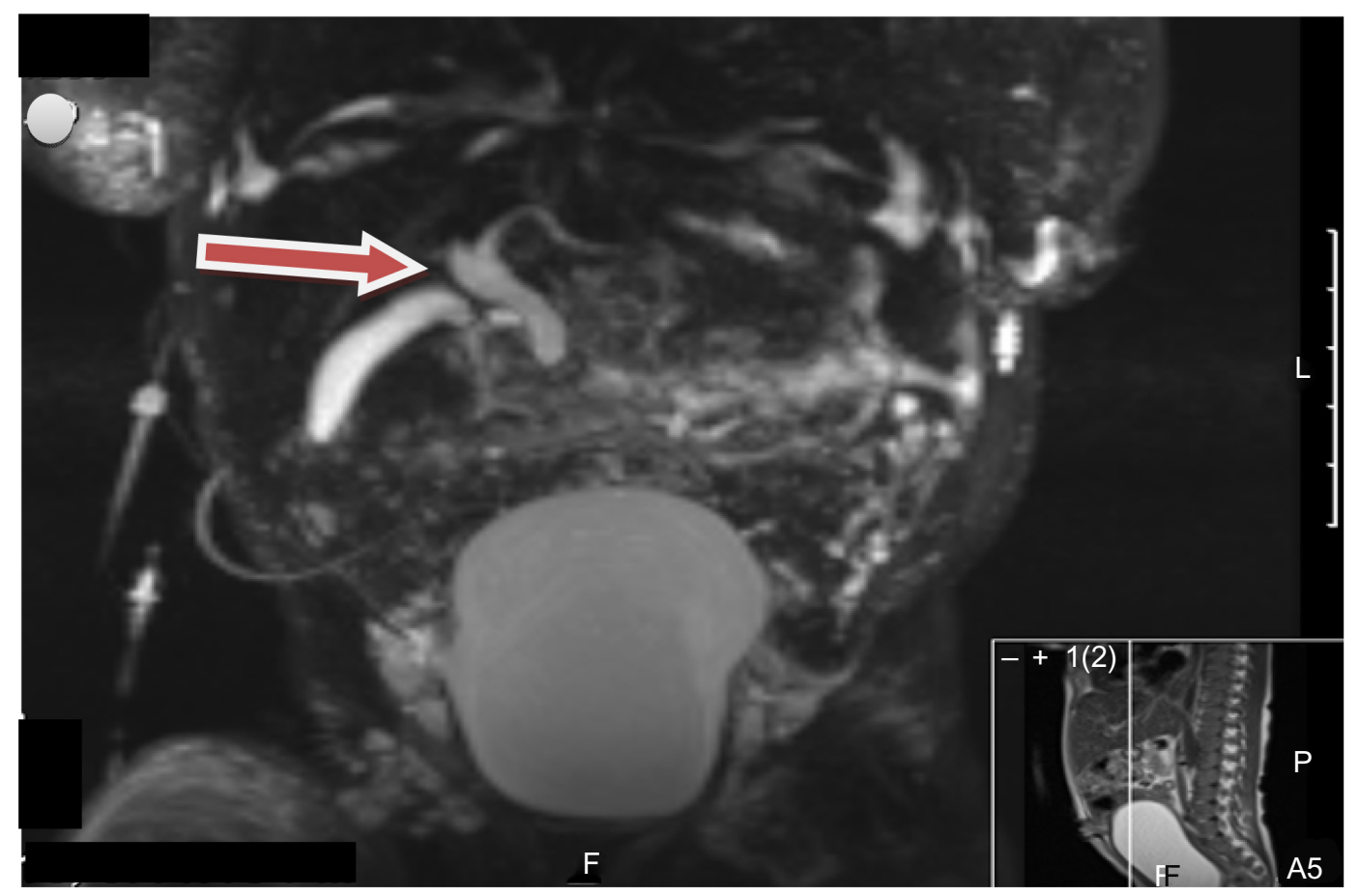

Figure 2 MRCP for better visualization of the choledochal cyst.

Note: MRCP revealed choledochal cyst (arrow) with extension involving distal aspects of right and left hepatic ducts.

Abbreviation: MRCP, magnetic resonance cholangiopancreatography; F, front; L, left; P, posterior. 

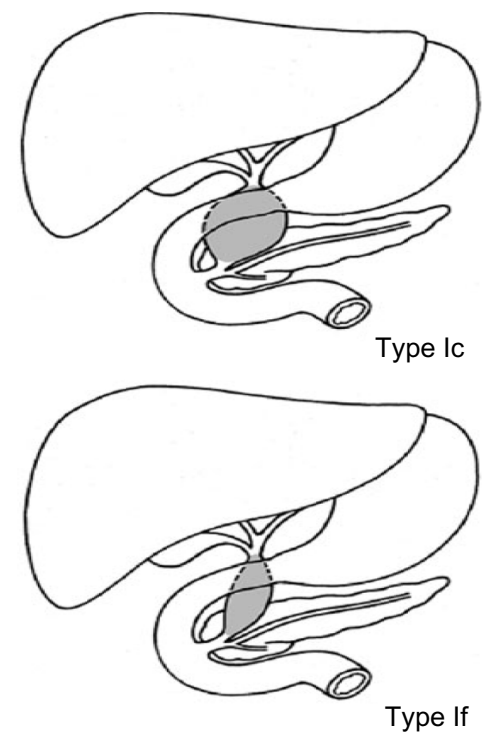
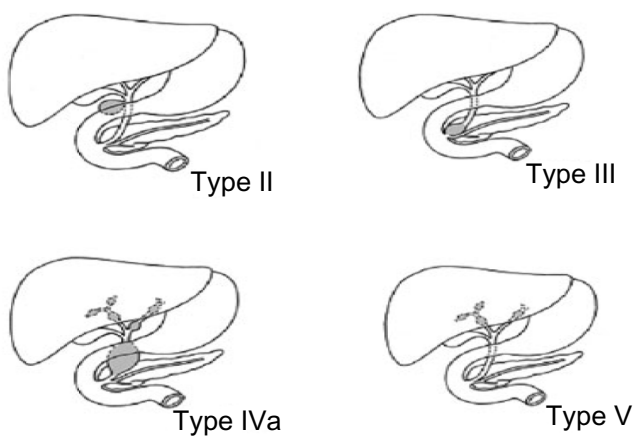

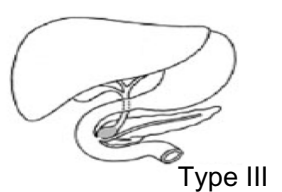

ype $V$

Figure 3 Todani classification of choledochal cysts.

Note: Reprinted from The American Journal of Surgery, I34(2), Todani T, Watanabe Y, Narusue M, Tabuchi K, Okajima K, Congenital bile duct cysts: Classification, operative procedures, and review of thirty-seven cases including cancer arising from choledochal cyst, 263-269, Copyright () (1977), with permission from Elsevier. ${ }^{19}$

Abbreviations: Type I, cystic (Ic) or fusiform (If); Type II, diverticulum; Type III, choledochocele; Type IV, multiple extrahepatic and intrahepatic duct cysts (IVa) or multiple extrahepatic duct cysts (IVb); Type $\mathrm{V}$, intrahepatic duct cysts (single or multiple).

congenital anomalies in chromosomally normal fetuses and neonates were genitourinary $(6.48 \%)$, followed by cardiovascular $(6.25 \%)$, and musculoskeletal anomalies. ${ }^{2-5}$ The gastrointestinal anomalies reported to be associated with single umbilical artery are cleft palate, imperforate anus, and esophageal atresia. ${ }^{4,6}$

Choledochal cyst, although a rare anatomic variation, is the most frequent malformation of the extrahepatic biliary ducts. $^{7}$

It may present at any age, but the clinical manifestation differs according to the age of onset. ${ }^{8}$ Usually, choledochal cysts present as abdominal pain, jaundice, and a palpable abdominal mass. Intermittent jaundice and an abdominal mass are the most common findings in infants. ${ }^{9}$ Neonates are only rarely asymptomatic, as found in our case. Other studies describe cases of choledochal cyst in asymptomatic newborns. ${ }^{10,11}$

Numerous pathologic, anatomic, and radiologic observations have stimulated various theories on the pathogenesis of this condition, but no theory has yet been able to explain the origin of this disorder satisfactorily. In recent years, the close association between anomalies of the pancreaticobiliary ductal junction and formation of choledochal cysts has been noted. The basic anomaly in the choledochal cyst formation is the embryological arrest of the migration of the pancreaticobiliary junction toward the duodenal wall. ${ }^{12}$

In the single umbilical artery, theories include primary agenesis of one of the umbilical arteries, secondary regression of a preexisting normally formed artery, or alternatively, persistence of the original single allantoic artery of the body stalk.

It is assumed that factors that could cause agenesis and regression of the umbilical vessel could also prevent or slow migration and/or multiplication of cells either: 1) by stopping tissue growth and development; or 2) by killing some cells already in that location causing a persistence of atresia or an anomaly in the hollow organ. ${ }^{13}$ This pathway might explain the slowing down and stoppage of cell migration that may have led to the common bile duct and pancreatic duct not uniting within the sphincter of Oddi instead forming the long common channel causing the choledochal cyst.

Choledochal cysts can be categorized according to their anatomic appearance into five types ${ }^{14}$ (Todani classification): type I, cystic (Ic) or fusiform (If); type II, diverticulum; type III, choledochocele (dilatation of the terminal common bile duct within the duodenal wall); type IV, multiple extrahepatic and intrahepatic duct cysts (IVa) or multiple extrahepatic duct cysts (IVb); and type V, intrahepatic duct cysts (single or multiple).

In one large series, type I cysts account for at least 75\% of all cases, and type IVa cysts account for most of the remainder; other varieties are rare. ${ }^{14}$

Ultrasonography is the best initial method of evaluating dilatation of the intrahepatic and extrahepatic bile ducts. ${ }^{15}$ Early diagnosis followed by cyst excision is the treatment of choice, even in asymptomatic children. ${ }^{8}$ 
The best treatment option is surgical. Optimal timing for cyst excision depends on variables, such as gestational age, weight, associated conditions, biochemical liver alterations, development of complications, and the sonographic surveillance of size. ${ }^{10}$ Surgical correction may be performed in neonates as early as several days of life. ${ }^{10}$ Surgery is usually Roux-en-Y hepaticojejunostomy. Conservative treatment is preserved only in the presence of complications like cholangitis or pancreatitis.

Complications of choledochal cysts include cholecystitis, recurrent cholangitis, biliary stricture, choledocholithiasis, recurrent acute pancreatitis, and malignant transformation into cholangiocarcinoma. ${ }^{16,17}$ When occurring alone, the single umbilical artery has little effect on infant prognosis, which is more dependent on associated malformations and gravid pathologies determining antenatal and postnatal management. ${ }^{18}$

\section{Conclusion}

We describe a novel association of type I choledochal cyst and single umbilical artery in an asymptomatic neonate. Congenital biliary duct dilatation is rare, and it has never been reported in association with a single umbilical artery. In the diagnosis, the ultrasound imaging is most important as a screening tool and magnetic resonance cholangiopancreatography as a method of adequate visualization.

\section{Acknowledgment}

We would like to thank Dr Lewis P Rubin, professor of Pediatrics and Biomedical Sciences, Texas Tech University Health Sciences Center, El Paso, TX, USA, for editorial assistance.

\section{Disclosure}

The authors report no conflicts of interest in this work.

\section{References}

1. Saller DN, Keene CL, Sun CC, Schwartz S. The association of single umbilical artery with cytogenetically abnormal pregnancies. Am J Obstet Gynecol. 1990;163(3):922-925.
2. Murphy-Kaulbeck L, Dodds L, Joseph KS, Van den Hof M. Single umbilical artery risk factors and pregnancy outcomes. Obstet Gynecol. 2010;116(4):843-850.

3. Hua M, Odibo AO, Macones GA, Roehl KA, Crane JP, Cahill AG. Single umbilical artery and its associated findings. Obstet Gynecol. 2010;115(5):930-934.

4. Martínez-Frías ML, Bermejo E, Rodríguez-Pinilla E, Prieto D; ECEMC Working Group. Does single umbilical artery (SUA) predict any type of congenital defect? Clinical-epidemiological analysis of a large consecutive series of malformed infants. Am J Med Genet A. 2008;146A(1):15-25.

5. Rittler M, Mazzitelli N, Fuksman R, de Rosa LG, Grandi C. Single umbilical artery and associated malformations in over 5500 autopsies: relevance for perinatal management. Pediatr Dev Pathol. 2010;13(6):465-470.

6. Chow JS, Benson CB, Doubilet PM. Frequency and nature of structural anomalies in fetuses with single umbilical arteries. J Ultrasound Med. 1998;17(12):765-768.

7. Al-Sinani S, Al Naamani K, Lutfi W, Al Hajri A. Choledochal cysts in Omani children: a case series. Arab J Gastroenterol. 2012;13(2): 89-92.

8. Miyano T, Yamataka A. Choledochal cysts. Curr Opin Pediatr. 1997;9(3):283-288.

9. Oldham KT, Hart MJ, White TT. Choledochal cysts presenting in late childhood and adulthood. Am J Surg. 1981;141(5):568-571.

10. Lugo-Vicente HL. Prenatally diagnosed choledochal cysts: observation or early surgery? J Pediatr Surg. 1995;30(9):1288-1290.

11. Rha SY, Stovroff MC, Glick PL, Allen JE, Ricketts RR. Choledochal Cysts: A Ten Year Experience. Am Surg. 1996;62(1):30-34.

12. Dumitrascu T, Lupescu I, Ionescu M. The Todani classification for bile duct cysts: an overview. Acta Chir Belg. 2012;112(5):340-345.

13. Staribratova D, Belovezhdov V, Milchev N, Batashki I, Apiosjan Zh. [Single umbilical artery (SUA)]. Akush Ginekol (Sofiia). 2010;49(1): 17-20. Bulgarian.

14. Todani T, Watanabe Y, Toki A, Morotomi Y. Classification of congenital biliary cystic disease: special reference to type Ic and IVA cysts with primary ductal stricture. J Hepatobiliary Pancreat Surg. 2003;10(5): 340-344.

15. Kim OH, Chung HJ, Choi BG. Imaging of the choledochal cyst. Radiographics. 1995;15(1):69-88.

16. Michaelides M, Dimarelos V, Kostantinou D, et al. A new variant of Todani type I choledochal cyst. Imaging evaluation. Hippokratia. 2011;15(2):174-177.

17. Irie H, Honda H, Jimi M, et al. Value of MR cholangiopancreatography in evaluating choledochal cysts. AJR Am J Roentgenol. 1998; 171(5):1381-1385.

18. Blache G, Garba A, Frairot P, Vancina S, Gaja R. [Prognostic value of a single umbilical artery. 87 cases]. J Gynecol Obstet Biol Reprod (Paris). 1995;24(5):522-528. French.

19. Todani T, Watanabe Y, Narusue M, Tabuchi K, Okajima K. Congenital bile duct cysts: Classification, operative procedures, and review of thirty-seven cases including cancer arising from choledochal cyst. The American Journal of Surgery. 1977;134(2):263-269.

\section{Publish your work in this journal}

Research and Reports in Neonatology is an international, peer-reviewed, open access journal publishing original research, reports, editorials, reviews and commentaries on neonatal health. The manuscript manage-
ment system is completely online and includes a very quick and fair

\section{Dovepress}

peer-review system. Visit http://www.dovepress.com/testimonials.php to read real quotes from published authors. 